\title{
Pediküllü fleplerdeki skarların flep yaşamına etkileri
}

\author{
The effects of the scars in pedicled flaps on flap survival \\ Ramazan Hakan Özcan
}

\section{Özet}

Amaç: Skar, doku bütünlüğünün bozulması sonucu yara iyileşme mekanizmalarının devreye girmesiyle meydana gelen ve oluştuğu bölgede kan akımını olumsuz etkileyen bir patolojidir. Bu çalışmada diğer flep seçeneklerinin başvurulmasına sebep olan, flep planlanacak bölgedeki skarların olumsuz etkilerini ve skarın yönünün değişmesiyle ne gibi farklılıklar olacağı araştıııldı.

Gereç ve yöntem: Çalışmada 24 adet Wistar Albino cinsi dişi rat kullanıldı. Ratların sırt bölgesinde ortadaki $1 \mathrm{~cm}$ 'lik sağlam deri adasının her iki tarafında $2 \times 6 \mathrm{~cm}$ 'lik kaudal tabanlı flepler planlandı. İlk 12 ratta transvers skar içeren sol flep transvers skar grubu ve skar içermeyen sağ flep kontrol grubu olarak değerlendirildi. Diğer 12 ratta oblik skar içeren sol flep oblik skar grubu ve skar içermeyen sağ flep kontrol grubu olarak değerlendirildi. Flep araştırması için oluşturulan gruplar 1. Grup kontrol grubu $(n=24)$ 2. Grup transvers skar grubu $(n=12) 3$. Grup oblik skar grubu $(n=12)$ olarak adlandırıldılar. Sol flep pedikülünde transvers ve oblik skar oluşturulmasını takiben 30. günde kontrol grubunu oluşturan sağ flepler ile çalışma grubunu oluşturan sol flepler eleve edildi ve kaldııılıkları bölgeye sütüre edildi. 4. günün sonunda ratlara eter ile anestezi ve ötenazi uygulandı. Her iki tarafta canlı kalan flep alanları milimetrik olarak ölçüldü. Skarıda içine alacak şekilde histopatolojik inceleme için çalışma ve kontrol fleplerinden biyopsiler alındı.

Bulgular: Her bir flebin toplam alanı $1200 \mathrm{~mm}^{2}$ ve $1000 \mathrm{~mm}^{2}$ dir. Transvers skar içeren ratlarda skarlı fleplerde nekroz olan flep alanı ortalaması $\% 80,8$ iken skarsız fleplerde bu oran $\% 57,6$ olarak bulundu. Oblik skar içeren ratlarda skar grubunda nekroza uğrayan flep alanı ortalaması $\% 83,9$ iken skarsız kontrol grubunda $\% 63,3$ tür. Histopatolojik bulgu olarak skarsız kontrol grubunda normal yapıda epidermis ve dermiş komponentleri görülürken her iki skar grubunda da epidermis ve dermiste atrofi, adneksiyal yapıların kaybı, retiküler dermisi tutan fibrozis görüldü.

Sonuç: Skar random flep canlılığını olumsuz yönde etkileyen bir faktördür. Skar yönü nekroz oranını değiştirmemiş̧tir. Skar distalinde kalan bir deri flebinin normalde yaşaması gereken kısmının ancak yarısının yaşayabileceği sonucuna varılmıştır.

Anahtar kelimeler: Flep, nekroz, pedikül, skar.

Özcan RH. Pediküllü fleplerdeki skarların flep yaşamına etkileri. Pam Tıp Derg 2020;13:803-812.

\begin{abstract}
Purpose: Scar is a pathology that occurs when the wound healing mechanisms take action as a result of the deterioration of tissue integrity and that adversely alects the blood flow in the region where it occurs. In this study, we investigated the negative effects of the exisiting scars in the area of scheduled flap, which led to the consideration of other flap options, and investigated the differences that would arise with the change of the direction of the scar.

Materials and methods: Twenty-four female Wistar Albino rats were used in the study. In the back region of the rats, a $2 \times 6 \mathrm{~cm}$ caudal-based flaps were planned on both sides of a $1 \mathrm{~cm}$ intact skin island. In the first 12 rats, the left flaps with transverse scar were included in the Group with transverse scar, and the right flaps without scar were included in the control group. In the other 12 rats, the left flaps with an oblique scar were included in the Group with oblique scar and the right flaps without scar were included in the control group.

The groups created for flap investigation were named as follows:

Group 1: The control group $(n=24)$

Group 2: The group with transverse scar $(n=12)$

Group 3: The group with oblique scar $(n=12)$

Following transverse and oblique scar formation in the left flap pedicle, the right flaps forming the control group and the left flaps forming the study group were elevated on the 30th day, and they were sutured in the site where they were elevated. At the end of the 4th day, rats were anesthetized with ether and euthanized. The surviving flap areas on both sides were measured in millimeters. Biopsies including the scars were taken from the study and control flaps for histopathological examination.

Results: The total area of each flap was $1200 \mathrm{~mm}^{2}$ and $1000 \mathrm{~mm}^{2}$. While the mean flap area with necrosis in scarred flaps was $80.8 \%$ in the rats with transverse scars, this ratio was found as $57.6 \%$ in scarless flaps. In
\end{abstract}


the rats with oblique scar, the mean flap area with necrosis was $83.9 \%$ in the scar group whereas it was $63.3 \%$ in scarless control group. As histopathological findings; while epidermis and dermis components in normal structure were seen in the scarless control group, atrophy in epidermis and dermis, loss of adnexal structures, and fibrosis involving reticular dermis were seen in both scar groups.

Conclusion: Scar is a factor that negatively a!ects the random flap viability. The direction of the scar did not change the necrosis rate. It has been concluded that only half of a skin flap, which is normally expected to survive, could survive in the distal region of a scar.

Key words: Flap, necrosis, pedicle, scar.

Ozcan RH. The effects of the scars in pedicled flaps on flap survival. Pam Med J 2020;13:803-812.

\section{Giriş}

Yara ve yara iyileşmesi konusu yüzyıllar boyu hekimlerin temel uğraş alanlarından birisini oluşturmuştur. Özellikle geniş defektli alanların örtülmesinde karşılaşılan problemler, hekimlerin bu konuda daha fazla araştırmacı kimliğe bürünmesine yol açmış ve bunun doğal sonucu olarak Plastik ve Rekonstrüktif Cerrahi bilimi doğmuştur [1-7].

Plastik ve Rekonstrüktif Cerrahi'nin tarihsel gelişiminde, defekt onarımı için gerekli dokusal desteğin sağlanmasında değişik teknikler ortaya çıkmıştır. Bu teknikleri basitten komplekse doğru sıralayacak olursak, primer sütür, greft ve flep ile onarımdır [1-6].

İnsan vücudunun anatomik olarak ikinci kez keşfi flep cerrahisi sayesinde olmuştur. Flep cerrahisi günümüze kadar çok çeşitli aşamalar kaydetmiştir [1, 6, 8, 9]. Random deri flepleri ile başlayan flep cerrahisi daha sonra tanımlanan aksiyal flepler, fasya flepleri, kompozit flepler, prefabrike flepler, venöz flepler ve mikrovasküler serbest doku aktarımları ile en uç noktaya ulaşmıştır.

Dermisi de içine alan tüm kesiler bir skar dokusu bırakarak iyileşirler. Kesinin derinliğine göre derinin kan desteğini sağlayan dermal, subdermal pleksus ve direk kutanöz damarların devamlılığı bozulur. Kesi bölgesinin doku bütünlüğünün sağlanmasından sonra neovaskülarizasyonla yeniden damarlanma meydana gelir. Fakat skar dokusunun perfüzyonu hiçbir zaman skarsız olduğu dönemdeki seviyesine ulaşamaz.

Flep cerrahisindeki baş döndürücü gelişmelerin ortaya çıkmasından önce uzak alanlardaki defektleri kapatmak için tüp flepler başarı ile kullanılmıştır [9, 10]. Tüp fleplerin en önemli özelliği 2. ve 3. evrelerinde bir skar tabanlı flep olarak kullanılıyor olmalarıdır. Genellikle $1 / 2$ en/boy oranında planlanan bu flepler iki paralel insizyon ve subdermal elevasyon yapılarak flep hem dley edilir hemde tüp haline getirilir. Altı haftalık maturasyon döneminden sonra tüp fleplerin bir ucu kesilerek taşıyıcı alana (genellikle el bileğinin radial kısmı) sütüre edilir. Flep bu aşamadan sonra hem verici alandan hem de el bileğindeki skar dokusundan beslenmektedir. En az iki buçuk haftalık bekleme döneminden sonra, flebin verici alandaki diğer ucu kesilerek tamamen skarlı pedikülden beslenmeye başlayan flep vücudun herhangi bir bölgesindeki defekte nakledilir.

Random pattern fleplerin herhangi bir besleyici aksiyal damarı olmadığı için pedikül bölgesinde skar olması, flep seçimini zorlaştıran en önemli faktördür. Litaratür araştırıldığında flep pedikülündeki skarların flep yaşamını ne oranda etkilediğini ve skarın yönünün bir etkisi olup olmadığını gösteren yeterli çalışma yoktur.

$\mathrm{Bu}$ çalışmada, özellikle renk ve doku uyumu açısından defekte komşu alanlardan hazırlanacak fleplerin üzerindeki skarların olumsuz etkilerini ve skar yönünün değişmesiyle ne gibi farklılıklar olacağını araştırmayı amaçladık.

\section{Gereç ve yöntem}

$\mathrm{Bu}$ çalışma Şişli Etfal Hastanesi Plastik ve Rekonstrüktif Cerrahi Kliniği Mikrocerrahi Araştırma Laboratuvarı'nda 2010 yılından önce yapılmıştır. Çalışma için ortalama ağırlıkları 210 gr (180-230) olan 24 adet Wistar-Albino cinsi dişi rat kullanıldı. $20^{\circ} \mathrm{C}$ sabit ısıda, 12 şer saat gündüz-gece periyodunda tutuldu. Beslenmelerinde standart rat yemi kullanıldı.

1. Grup: Kontrol grubu $(n=24)$

2. Grup: Transvers skar grubu $(n=12)$ 


\section{Grup: Oblik skar grubu $(n=12)$}

Tüm skar oluşturulması ve fleplerin kaldırılması uygulamaları eter ile inhalasyon anestezisi altında yapıldı. Operasyon bölgeleri her girişim öncesi traşlanıp \%10 povidon iyot ile temizlendi. 12 rat içeren 2. grup (transvers skar grubu) flep pedikülünün planlandığı sıçanların sol dorsal kaudal bölgesinde, kuyruk kökünden $3 \mathrm{~cm}$ uzakta medial kenarı kolumna vertebralisin $0,5 \mathrm{~cm}$ lateralinde olacak şekilde $2 \mathrm{~cm}$ uzunluğunda derin muskuler fasyaya kadar ulaşan deri ve pannikulus karnozusu içeren transvers kesi yapılarak dikilip transvers skar grubunun skarları oluşturuldu. Diğer 12 ratı içeren 3. grup (oblik skar grubu) flep pedikülünün planlandığı sıçanların sol dorsal kaudal bölgesinde, $2 \mathrm{~cm}$ genişliğinde flep hazırlanmasına olanak sağlayan kuyruk kökünden medial sınırı $5 \mathrm{~cm}$ lateral sınırı $3 \mathrm{~cm}$ uzaklıkta olan transvers hat ile $45^{\circ}$ lik açı yapan oblik kesi 2. gruptaki ile aynı derinlikte kesilerek dikilip oblik skar grubunun skarları oluşturuldu (Resim 1). Tüm gruplarda yara maturasyonunun tamamlanması için 30 gün beklendi.

Kontrol grubu: Kontrol grubu olarak her iki gruptaki sıçanların sağ dorsal alanları kullanıldı. Çalışma grubu olarak seçilen ve dorsal sol taraflarda skar oluşturulan sıçanların dorsal sağ taraflarından kontrol flepleri kaldırıldı. Kontrol flepleri skar oluşturulmasından 30 gün sonra, yara maturasyonunun tamamlanmasını takiben skarlı flepler ile birlikte, aynı boyutlarda kaldırıldı. Fleplerin tabandan beslenmesini engellemek için tabana steril polietilen örtü yerleştirildi. Flep kaldırıldığı bölgeye 4/0 atravmatik ipek sütürler ile yeniden dikildi.
Transvers skar srubu: Otuzuncu günün sonunda denekler eterle inhalasyon anestezisi ile uyutuldu. Önceden oluşturulan skar bulunup işaretlendi. Rat dorsal bölgesinin sol tarafından $2 \times 6 \mathrm{~cm}$ boyutlu skar tabanlı flep sağ tarafından aynı boyutta kontrol flebi kaldırıldı. Fleplerin tabandan beslenmesini engelliyecek şekilde derin muskuler fasya üzerine steril polietilen örtü konularak flepler kaldırıldıkları bölgeye 4/0 ipek sütür ile dikildi (Resim 2A). Her biri ayrı kafeste tutulan denekler 4 . günün sonunda eter ile uyutularak çalışma ve kontrol bölgelerindeki fleplerin canlı kalan flep alanları milimetrik olarak ölçülerek morfometrik inceleme için alanları hesaplandı (Resim 2B). Histopatolojik inceleme için skarıda içine alacak şekilde çalışma ve kontrol fleplerinden biyopsiler alındı.

Oblik skar grubu: Transvers skar grubunda olduğu gibi rat dorsallerinde oblik skarlı bölgeden ve karşı taraftan 2x6 cm'lik flepler kaldırılarak yerlerine dikildi (Resim 3A). $\mathrm{Bu}$ grupta da 4. günün sonunda anestezi altında canlı kalan flep alanları hesaplandı ve histopatoloji için numuneler alındı (Resim 3B). Oblik skarlı flebin skar distalinde kalan, yaşayan flep bölümü dikkate alındı (Resim 4 “A”). Kontrol grubu flepte yaşayan tüm flep alanından 200 $\mathrm{mm}^{2}$ (oblik skar grubunda dikkate alınmayan skar proksimalindeki üçgen alan) (Resim 4 "B") çıkarılarak değerlendirmeye alınacak alan tesbit edildi.

İstatistik: Çalışma sonucunda, sayısal olarak ifade edilen bulguların istatistiki değerlendirmesi "t testi" ile yapıldı.

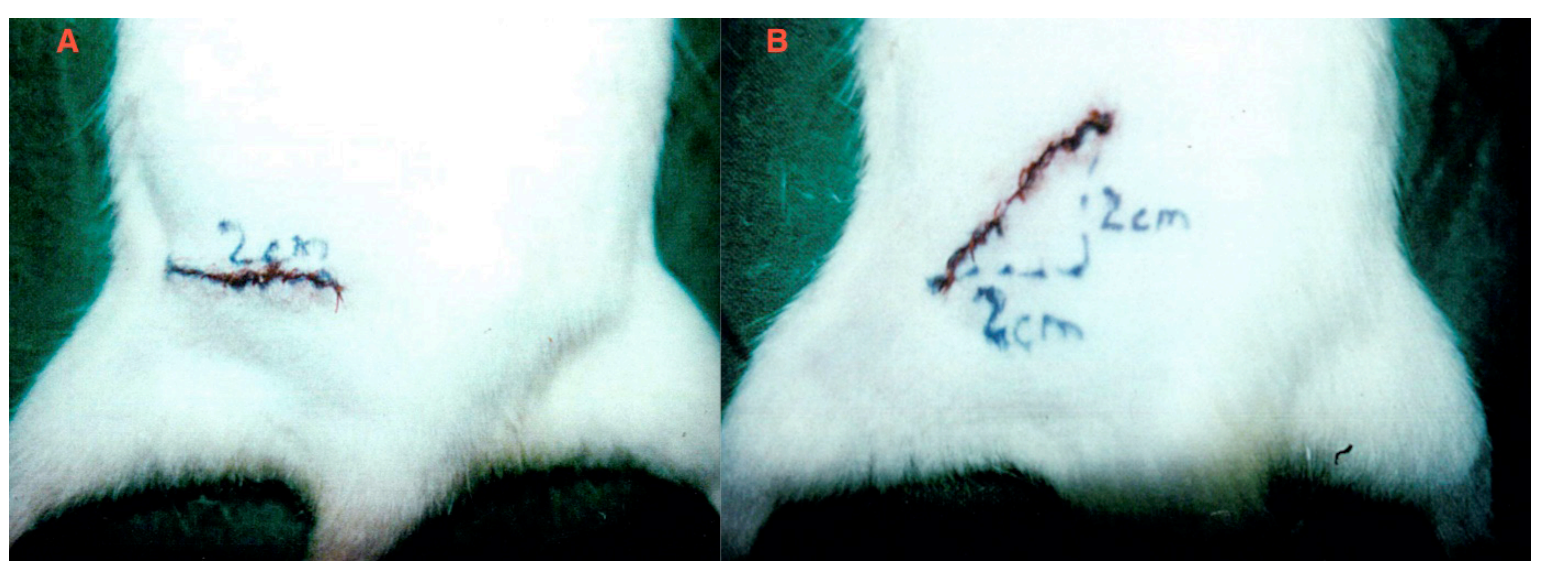

Resim 1. Transvers ve oblik skarın oluşturulup dikilmesi 


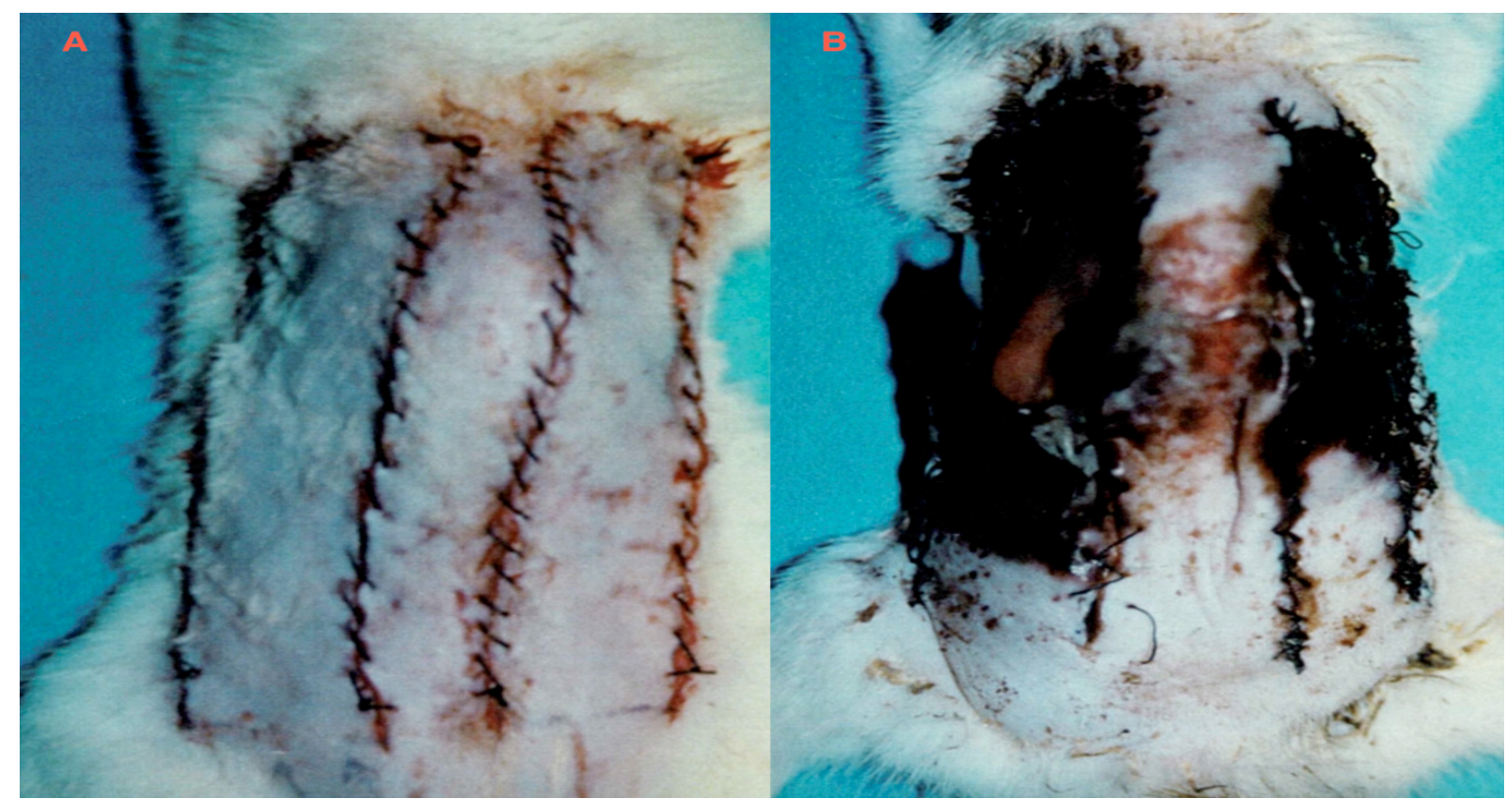

Resim 2A. Transvers skar tabanlı ve kontrol fleplerinin kaldırılıp yerine dikilmiş hali

2B. Postoperatif 4. günde canlı kalan flep alanlarının görüntüsü

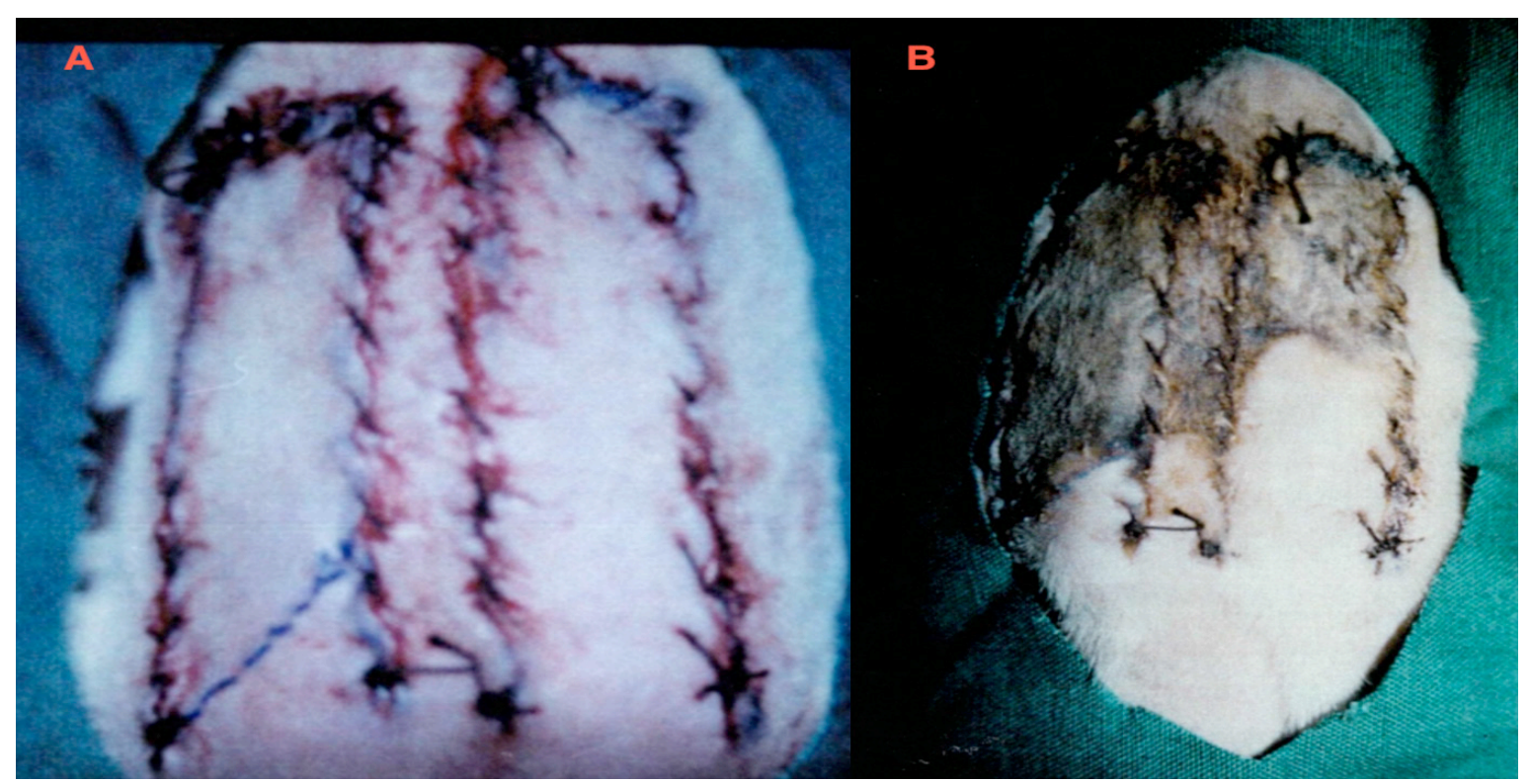

Resim 3A. Oblik skar tabanlı ve kontrol fleplerinin kaldırılıp yerine dikilmiş hali 3B. Postoperatif 4. günde canlı kalan flep alanlarının görüntüs 


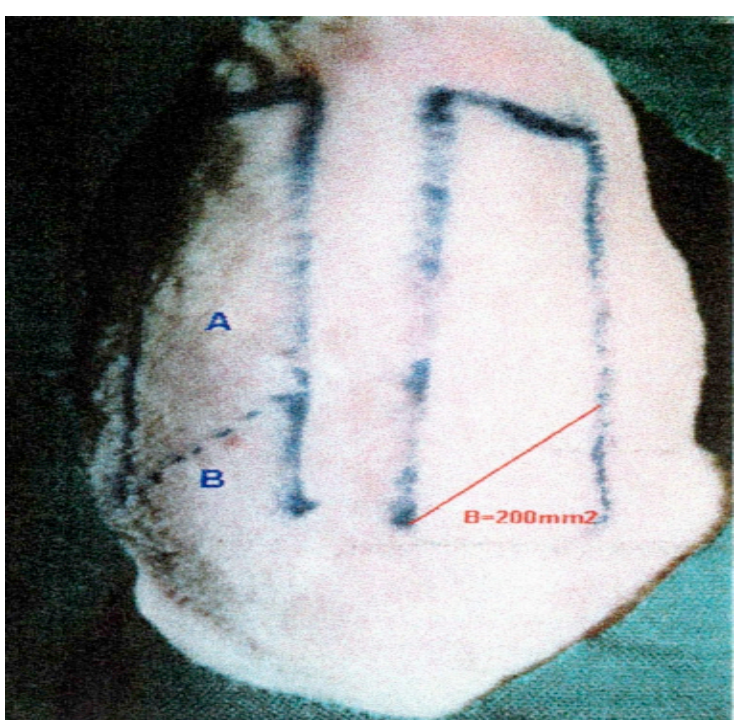

Resim 4. Oblik skar tabanlı flepte hesaba dahil edilecek(A) ve edilmeyecek(B) flep alanları.

Histopatolojik değerlendirme: Ratlardan alınan biyopsi örnekleri \%10'luk formaldehit solüsyonuna kondu. Parafin bloklara gömüldü. Mikrotom ile 5 mikron kalınlıkta elde edilen kesitler hematoksilen eosin ile boyanıp ışık mikroskobunda değerlendirildi.

\section{Bulgular}

Transvers skar grubundaki deneklerden 2 tanesi ve oblik skar grubundaki deneklerden 3 tanesi fleplerin kaldırıldığı aşamada kaybedildi. Çalışma transvers skar grubundan 10, oblik skar grubunda 9 denek ile tamamlandı.

Postoperatif 1. günde fleplerin beslenemeyen kısımlarında soğukluk ve siyanozun başladığı görüldü. Postoperatif 2. günde belirmeye başlayan nekroz sınırlarının 4. günde tam olarak kesinleştiği saptandı.

Transvers skar grubu: Çalışma ve kontrol flepleri eleve edildikten sonra sağ femoral venden girilerek intravenöz flourescein verildi. 5 dakika sonra karanlık odada wood ışığı altında skarlı fleplerde pedikülden distale doğru flourescein boyasının ya hiç geçmediği ya da çok az bir kısmının boyandığı görüldü. Kontrol flebinde ise boyanın pedikülden $2 \mathrm{~cm}$ kadar distale ilerlediği gözlendi (Resim 5).

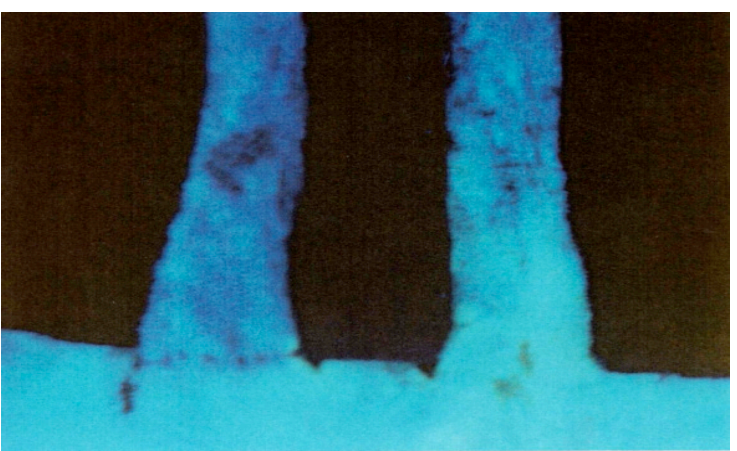

Resim 5. Flourescein boyasının skarlı flepte skarı geçemediğini ve skarsız flepte $2 \mathrm{~cm}$ kadar boyanmanın görüldüğü resim.

Transvers skar grubunda skarlı ve skarsız taraflarda hazırlanan fleplerin toplam alanları 1200 mm²'dir. Canlı kalan flep alanları ölçülmüş olup Tablo 1'de görülmektedir. Skarlı ve kontrol grubu fleplerde canlı kalan flep alanları karşılaştırıldığında skarlı tarafta yaşayan flep alanı skarsız tarafta yaşayan flep alanının yarısından daha az olmuştur. Skarlı fleplerde ortalama canlı kalan alan $230 \mathrm{~mm}^{2}$ iken skarsız fleplerde bu alan $508 \mathrm{~mm}^{2}$ dir. Skarlı flep ve skarsız flep ortalamalarının birbirine oranı 0,452 'dir. $T$ testi ile yapılan istatistiki değerlendirme sonucu transvers skarlı grup ile skarsız kontrol grubu arasında canlı kalan flep alanları arasındaki fark anlamlı bulunmuştur. $p=0,000862$

Oblik skar grubu: Oblik skar grubunda da flourescein ile yapılan dolaşım testinde transvers skar grubunda olduğu gibi boyanın skar distaline geçmediği ya da çok az geçtiği gözlendi. Oblik skar grubunda, skarlı ve skarsız taraflarda hazırlanan fleplerin değerlendirmeye alınan toplam alanları $1000 \mathrm{~mm}^{2}$ dir. Canlı kalan flep alanları ölçülmüş olup Tablo 2'de görülmektedir. Skarlı grupta canlı kalan flep alanı ortalaması $160 \mathrm{~mm}^{2}$ iken skarsız kontrol grubu fleplerin ortalaması $366,6 \mathrm{~mm}^{2}$ dir. Oblik skarlı fleplerde de canlı kalan flep alanı, diğer grupta olduğu gibi skarsız kontrol fleplerinin yarısından az olmuştur. Canlı kalan skarlı flebin skarsız flebe oranı 0,436 dır. Oblik skar grubunda da canlı kalan flep alanlarının skarsız flep alanlarına oranı istatistiki olarak anlamlı bulunmuştur. $p=0,001086$ 
Tablo 1. Transvers skar grubunda canlı kalan skarlı ve skarsız flep alanları $\left(\mathrm{mm}^{2}\right)$

\begin{tabular}{lll}
\hline Denek & Skarlı flep $\left(\mathbf{m m}^{2}\right)$ & Skarsı flep $\left(\mathbf{m m}^{2}\right)$ \\
\hline $\mathbf{1}$ & 330 & 660 \\
$\mathbf{2}$ & 630 & 700 \\
$\mathbf{3}$ & 140 & 320 \\
$\mathbf{4}$ & 140 & 310 \\
$\mathbf{5}$ & 190 & 610 \\
$\mathbf{6}$ & 190 & 570 \\
$\mathbf{7}$ & 180 & 620 \\
$\mathbf{8}$ & 260 & 710 \\
$\mathbf{9}$ & 120 & 300 \\
$\mathbf{1 0}$ & 120 & 280 \\
Ortalama & $\mathbf{2 3 0}$ & $\mathbf{5 0 8}$ \\
\hline
\end{tabular}

Tablo 2. Oblik skar grubunda canlı kalan skarlı ve skarsız flep alanları $\left(\mathrm{mm}^{2}\right)$

\begin{tabular}{ccc}
\hline Denek & Skarlı flep $\left(\mathbf{m m}^{\mathbf{2}}\right)$ & Skarsız flep $\left(\mathbf{m m}^{\mathbf{2}}\right)$ \\
\hline 1 & 310 & 540 \\
2 & 90 & 230 \\
3 & 240 & 240 \\
4 & 30 & 350 \\
5 & 220 & 430 \\
6 & 290 & 490 \\
7 & 80 & 210 \\
8 & 110 & 280 \\
9 & 70 & 530 \\
Ortalama & 160 & $\mathbf{3 6 6 . 6}$ \\
\hline
\end{tabular}

Transvers skar grubu ile oblik skar grubunda canlı kalan flep alanları karşılaştıııldığında aralarında istatistiki olarak anlamlı bir fark gözlenmemiştir. $p=0,135648$

Histopatolojik bulgular: Histopatolojik değerlendirmede skarsız flepler ile her iki skarlı grup fleplerin karşılaştırması yapıldı. Skarsız fleplerde normal yapıda dermis ve epidermis komponentleri izlendi (Resim 6A). Transvers skar ve oblik skar grubunun her ikisinde de skar bölgesi ve distalinde kalan alanlarda epidermis ve dermiste incelme, tüm retiküler dermisi tutan yoğun fibrozis, adneksiyal yapılarda atrofi gözlemlendi (Resim 6B).

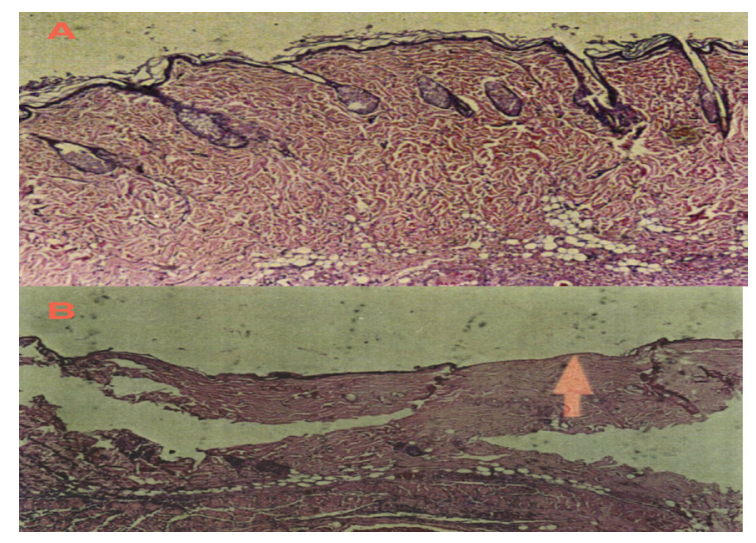

Resim 6A. Skarsız flep; Normal epidermal ve dermal yapılar. Hematoksilen eozin X40

6B. Skarlı flep; Atrofik epidermal ve dermal komponent. Hematoksilen eozin X40 


\section{Tartışma}

Flep cerrahisinde flep planlanan bölgede bir skarın bulunması, daima cerrahları korkutan ve başka seçenekler aramalarına neden olan bir sorun olmuştur. Özellikle baş ve boyun gibi, doku uyumu nedeniyle çevre doku ile onarımın gerekli olduğu alanlarda skarlar onarımı hayli güç hale getirmektedir.

Literatür araştırmalarımızda, kaynak bulunmakta bir hayli zorlandığımız flep üzerindeki skarların, bazı parametrelere göre flep hayatiyetini değişen oranlarda etkileyeceği hipotezi ile çalışmaya başladık. Bu parametreler, flep aksına göre skarın konumu, skar oluşma zamanı, skarın flepteki boyutu, dley işleminin olumlu etkilerinin olup olmadığı ve farmakolojik ajanların rolü gibi faktörlerdir.

Bir skar oluşumu ile sonuçlanan yara iyileşmesinin incelenmesinde değişik hayvan türleri kullanılmıştır (rat, tavşan, köpek, domuz, vb.). İyileşme süreci bu hayvanlar arasında ve insanlara göre de farklılıklar göstermektedir. Deri anatomisindeki farklılığında bunda rolü vardır. Sıçan, tavşan, köpek gibi deneysel çalışmalarda çokça kullanılan bu hayvanlarda subkütan panniculus carnosus kası mevcuttur ve predominant olarak gevsek bir deriye sahiptirler. $\mathrm{Bu}$ hayvanların deri olarak kanlanması panniculus carnosus içerisinde uzanan damarlar ile olmaktadır [11, 12]. İnsana en yakın deri dolaşımına sahip domuzlarda ise muskulokütan perforatörler derinin vasküler kaynağıdır [11].

Doku beslenmesinin araştırıldığı çalışmalarda domuzun daha iyi bir model olmasına rağmen, ucuz maliyet, kolay bakım ve daha kolay müdahale edilebilmesi nedeniyle sıçanlar sık olarak kullanılır [13]. Eter anestezisi kısa cerrahi işlemlerde pratik olmasına karşın kontrolü hayli zordur. Odun talaşı içerisinde beslenen sıçanlarda sıkça gelişen kronik obstrüktif akciğer hastalığı, bu kontrolü daha da zorlaştırmaktadır. Bu tür ölümlere literatürde de rastlanmaktadır [14]. Bizim deneklerimizden de 5 tanesi ikinci girişim sırasında eter anestezisini tolere edemeyerek kaybedildi ve çalışma dışı bırakıldı.

$\begin{array}{lr}\begin{array}{c}\text { Sıçan ve domuz } \\ \text { neovaskülarizasyonun }\end{array} & \begin{array}{r}\text { kularak } \\ \text { incelendiği }\end{array} \\ \text { Tsur'un }\left[\begin{array}{ll}15,16] & \text { çalışmasında fleplerde }\end{array}\right. \\ \text { neovaskülarizasyonun başlama süresi hakkında }\end{array}$

anlamlı bir fark bulunamamıştır. Aynı çalışmada, neovaskülarizasyonda flep tabanı dominant olmakla beraber yara kenarlarının da önemli rol ovnadığı sonucuna varılmıştır. Fleplerde neovaskülarizasyonun tabandan olduğu kadar yara kenarlarından da gerçekleştiğinin bilinmesi, skar distalinde kalan flep alanının tam olmasa da belirli bir kısmının yaşayabileceği gerçeğini ortaya koymuştur. Bir flebin skarlı bir alandan beslenmesi ilk olarak düşünülmüş değildir. Aksiyal, fasyokütan ve muskulokütan fleplerin keşfinden önce uzak alanlardan taşınan indirek fleplerde skarlı bir taban kullanılmıştır [10-17]. Bir indirek tüp flep olan, torakoabdominal bölgeden vasküler bir pediküle dayanılarak hazırlanan jump flebini Morgan [18] geniş doku defektlerinin kapatılmasında, Gibraiel [19] tarafından boyunun yanık skarı kontraktürlerinde, Kurata diz rekonstrüksiyonunda, Fukuda ise kranial bölgenin rekonstrüksiyonunda başarı ile kullanan otörlerdir. İkinci evrelerinde bir skar tabanını kullanacak olan tüp flepler, ilk aşamada $1: 1,5$ veya $1: 2$ oranında planlanarak dley edilmişlerdir. Fleplerin dley ile transferleri arasında geçen optimal sürenin belirlenebilmesi amacıyla pek çok çalışma yapılmıştır [11, 17, 20 , 21]. Kan akımının yönünün insizyondan sonra insizyona paralel olarak değiştiği, önce vazodilatasyon, sonra anjiogenez olduğu gösterilmiştir. Yapılan bir sıçan çalışmasında delay işleminin neovaskülarizasyona etkisinin 6. haftada en üst düzeye çıktiğı ve 30 . haftaya kadar sabit bir şekilde devam ettiği ve daha sonra azalmaya başladığı iddia edilmiştir [22]. Myers [4] bir çalışmasında maksimal faydanin sıçanlarda 42, tavşan ve domuzda 7 gün olduğu bildirilmiştir. Dley üzerine yapılan Reinisch [23]'in denerve A-V şant teorisine göre; eğer sempatik innervasyon sağlamsa dley fenomeni etkisizdir. Yukarıda başarılı sonuçlarını verdiğimiz tüp fleplerin bizim çalışmamızdan tek farkı dley işleminin uygulanmış olmasıdır. Çalışmamızda kullanmadığımız dley işleminin, bu örneklerden faydalanarak, skar tabanlı fleplerde canlı kalan flep alanını artıracağı inancındayız.

Flep distalinde oluşan nekrozu önlemek amacıyla birçok farmakolojik ajan denenmiştir. Monteiro [24] oral verilen pentoxifilinin sıçanlarda deri fleplerinin survisini \%50 oranın da artırdığını bildirmiştir. Fakat Chu [25]'nun 1990 yılında tavşanlar üzerinde yaptığı bir araştırma sonucuna göre, pentoxifilin verilen grup ile kontrol grubu arasında flep viyabilitesi 
açısından anlamlı bir fark bulunamamıştir. Emer [26] ve ark. bir $\mathrm{Ca}^{++}$kanal blokörü olan nifedipin'i sıçan dorsal deri fleplerinde kullanmış ve random deri fleplerinde nekrozun önlenmesinde bir etkisi olmadığını göstermiştir. Domuzlarda deri ve kas-deri fleplerinde kapiller kan akımı üzerine glukokortikoitlerin etkisinin araştırıldığı Nakatsuka [27] ve ark.'nın çalışmasında, metilprednizolon'un her iki parametre içinde terapötikbiretkiyesahipolmadığı ortayaçıkmıştır. Biz skar dokusunun ve skarın yönünün flep üzerine etkilerini araştırdığımız çalışmamızda, etkinliği kanıtlanmış farmakolojik ajanların skar tabanlı fleplere faydalı olabileceği inancındayız.

Silverman ve ark. [28], konvansiyonel flourescein testini( Wood lambası ile) kantitatif ölçüm yaptıkları test ile karşılaştırdıklarında, \%37 olguda flourescein ile boyanmamış alanda canlılık saptamışlardır. Bizim deneklerimizde de flepelevasyonundansonraverdiğimizfloruescein boyasının fleplerde ulaştığı sınırdan, postop 4. gün yapılan ölçüm sınırının fazla olması, aynı sonuca ulaştığımızı göstermektedir. Fleplerin boyutu hazırlandıkları bölgeye, herhangi bir aksiyal damar içerip içermemelerine, dley uygulanıp uygulanmamasına, hastanın özelliklerine göre çok farklılık göstermektedir. Deneysel çalışmalar, deri fleplerinde flebin enindeki değişikliklerin yaşayan flep boyutunda önemli farklılıklar oluşturmadığını göstermiştir. Snell [29] ise domuzlarda $3 \mathrm{~cm}$ 'nin altındaki fleplerde yaşayan flep boyutunun eni ile doğru orantılı olarak arttığıni göstermiştir.

Morita ve ark. [30] serbest flep planlanan orta hat abdominal skarlı iki hastada, indosiyanin yeşili ile yaptıkları anjiografik çalışmada, skarın deri dolaşımını aşırı olumsuz etkilediğini gözlemlemişlerdir. Skarlı bölgeden flep kaldırılacak ise mutlaka anjiografik çalışma ile skar distalinde kalan bölgenin kanlanıp kanlanmadığının ortaya konmasını önermektedirler.

Nykiel ve ark. [31] 169 hastayı içeren çalışmasında, intraabdominal geçirilmiş operasyonlara bağlı skarların, meme rekonstrüksiyonu için abdominal bölgeden hazırlanan serbest flep ameliyatları sonrası \%19 oranında flep komplikasyonları (2 total flep kaybı ve parsiyel kayıplar), \%19 oranında donör alanda yara iyileşme sorunları ile karşılaşılmıştır.

Yılmaz ve ark. [32] ratlar üzerinde kesi ve eksizyon ile yaptıkları deneysel skar modeli çalışmalarında, skar oluşumundan 7, 21 ve 42. günlerde flepleri kaldırmışlardır. 7. ve 21. günlerde kaldırılan skarlı fleplerin yaşayan kısmı birbirine benzer oranda iken 42. günde kaldırılan fleplerin yaşayan alanlarının istatistiki olarak daha fazla olduğunu gözlemlemişlerdir. Yine aynı çalışmada kesi yapılıp dikilen fleplerin eksizyon yapılan fleplere göre daha fazla kısmının yaşadığı sonucuna ulaşmışlardır. Bizim çalışmamıza en benzer olan bu çalışmada canlı kalan skarlı flep alanları $\% 82$ ve $\% 70$ gibi oranlarda daha fazla bulunmuştur. Bu sonuçta araştırmacıların çalışmayı abdominal bölgeden hazırlanan flep ile yapmış olmalarının etkisinin olabileceği kanaatindeyiz.

Flep pedikülü üzerinde bulunan skarlar flep yaşayabilirliğini olumsuz yönde etkilemektedir. Flebin enini tam olarak kateden, transvers ve oblik skarların yönleri, skar distalinde canlı kalacak flep boyutunu önemli oranda değiştirmemektedir.

Skarların flep yaşayabilirliği üzerine olan olumsuz etkilerinin azaltılması için skarın flepteki boyutu, skar oluşma zamanı, delay uygulaması ve farmakolojik ajanların kullanılması gibi parametrelerle ilave çalışmaların yapılması gereklidir.

Sonuç olarak, flep tabanındaki skarların flep yaşayabilirliğini ne oranda etkilediğinin ve skarın yönünün canlı kalan flep alanı üzerine araştırıldığı bu çalışmamızdan elde ettiğimiz sonuçlar, şu şekilde sıralanabilir;

*Skar flep canlılığını olumsuz yönde etkileyen bir faktördür.

*Flep pedikülündeki transvers skarlar canlı kalacak flep boyutunu \%55 oranında azaltmışlardır.

*Flep pedikülündeki $45^{\circ}$ 'lik oblik skarlar canlı kalacak flep boyutunu \%56 oranında azaltmışlardır.

*Flep canlılığı üzerine transvers skarın ve $45^{\circ}$ 'lik oblik skarın olumsuz etkileri hemen hemen aynıdır.

*Her iki skarlı flep histopatolojik olarak aynı değişiklikleri göstermişlerdir. Bu veriler ışığında, skar distalinde kalan bir deri flebinin normalde yaşaması gereken bölümünün ancak yaşayabileceği görüldü. Bizim flep aksına göre skarın konumunu araştırdığımız çalışmamızın, 
skarın oluş zamanı, skarın flepteki boyutu, delay uygulanmasiıve farmakolojik ajanların rolü gibi parametreler ile desteklenerek skarın olumsuz etkilerinin en aza indirilmesine çalışılmalıdır.

Çıkar ilişkisi: Yazar çıkar ilişkilerinin olmadığını beyan eder.

\section{Kaynaklar}

1. Converse MJ. Intraduction to plastic surgery. In: reconstructive plastic surgery. W. B. Saunders Company, Philadelphia 1977;1:3-69.

2. Cormack GC, Lamberty BGH. Introduction: the arterial anatomy of skin flaps. 1nd ed. Edinburgh, London, Melbourne and New York: Churchill Livingstone 1986;1-9.

3. Çağdaş A, Akın Y, Songür E. Plastik ve rekonstrüktif cerrahiye giriş. İzmir: Ege Ünv Yayın 1988;1-15.

4. Daniel RK, Kerrigan CL. Principles and physiology of skin flap surgery. Plastic Surgery. Philadelphia: WB Saunders Company 1990;1:275-281.

5. Fisher J, Gingrass MK. Basic principles of skin flaps. Plastic, maxillofacial and reconstructive surgery. 3nd ed. Baltimore: Williams\&Wilkins 1997;19-30.

6. Jankauskass S, Cohen IK, Grabb WC. Basic techniques of plastic surgery. Grabb and Smith, Plactic Surgery 4nd ed. Boston, Toronto, London: Little Brown and Company 1991;1-91.

7. McCarthy JG. Introduction to plastic surgery. Philadelphia: WB Saunders Company 1990;1:1-20

8. George B, Lamberty H. Flaps: Physiology, principles of design and pitfalls. Mastery of plastic and reconstructive surgery. Boston, New York, Toronto, London: Little, Brown and Company 1994;1:56-70

9. Grabb WC. Smith JW. Basic techniques of plastic surgery. 2nd ed. Boston, New York, Toronto, London: Little, Brown and Company 1973;81-89.

10. Strauc MF, Strauc WE. Tubed skin flaps.1nd ed. Boston, Toronto, London: Little, Brown and Company, 1975;405-409.

11. Callegari PR, Taylor GI, Caddy CM, Minabe T. An anatomic review of the delay phenomenon: I. Experimental studies. Plast Reconstr Surg 1992;89:397-407.

12. Dunn R. M, Mancoll J. Flap models in the rat. A review and reappraisal. Plast Reconstr Surg 1992;90:319328.

13. Cohen IK, Mast BA. Models of wound healing. J Trauma 1990;30:149-155.

14. Clarke HM, Howard CR, Pynn BR, et al. Delayed neovascularization in free skin flap transfer to irradiated beds in rats. Plast Reconstr Surg 1985;75:560-564. https://doi.org/10.1097/00006534-198504000-00021
15. Sefarin D, Shearin JC, Georgiade NG. The Vascularization of free flaps. Plast Reconstr Surg 1977;60:233-241. https://doi.org/10.1097/00006534197708000-00010

16. Tsur H, Daniller A, Strauch B. Neovascularization of skin flaps: route and timing. Plast Reconstr Surg 1980;66:85-93. https://doi. org/10.1097/00006534-198007000-00017

17. Connelly JR. Reconstructive procedures of the lower extremity. 2nd ed. Baltimore: J.W. Plastic Surgery 1973;919-924.

18. Morgan SC, Zbylski JR. Repair of massive soft tissue defects by open jump flaps. Plast Reconstr Surg 1972;50:265-269. https://doi.org/10.1097/00006534197209000-00012

19. Gibraiel EA. The jump flap procedure in the treatment of burn scar contractures of the neck. Br J Plast Surg 1971;24:289-292. https://doi.org/10.1016/s00071226(71)80072-3

20. Alexander MG.Jr. Study of delay phenomenon in axial pattern flaps in pigs. Plast Reconstr Surg 1979;63:550554. https://doi.org/10.1097/00006534-19790400000018

21. Finseth F, Cutting C. An experimental neurovascular island skin flap for the study of the delay phenomenon. Plast Reconstr Surg 1978;61:412-420. https://doi. org/10.1097/00006534-197803000-00016

22. Thomson FM, Beracha GJ, Guthrie RH.Jr. The effective duration of the delay phenomenon in the rat. Plast Reconstr Surg 1977;60:384-389.

23. Reinisch JF. The pathophysiology of skin flap circulation. Plast Reconstr Surg 1974;54:585-598. https://doi.org/10.1097/00006534-197411000-00010

24. Monteiro DT, Santamore WP, Nemir P.Jr. The influence of pentoxifylline on skin flap survival. Plast Reconstr Surg 1986;77:277-281. https://doi. org/10.1097/00006534-198602000-00019

25. Chu BC, Deshmukh N. The lack of effect of pentoxifylline on random skin flap survival. Plast Reconstr Surg 1989;83:315-318. https://doi.org/10.1097/00006534198902000-00021

26. Emery FM, Kodey TR, Bomberger RA, Mc Gregor DB. The Effect of nifedipine on skin flap survival. Plast Reconstr Surg 1990;85:61-63. https://doi.org/10.1097/00006534199001000-00011

27. Nakatsuka T, Pang CY, Neligan P, et al. Effect of glucocorticoid treatment on skin capillary blood flow and viability in cutaneous and myocutaneous flaps in the pig. Plast Reconstr Surg 1985;76:374-383. https:// doi.org/10.1097/00006534-198509000-00006 
28. Silverman DG, La Rossa, DD, Barlow $\mathrm{CH}$, et al. Quantification of tissue fluorescein delivery and prediction of flap viability with the fiberoptic dermofluorometer. Plast Reconstr Surg 1980;66:545553. https://doi.org/10.1097/00006534-19801000000007

29. Stell PM. The pig as an experimental model for skin flap behaviour: a reappraisal of previous studies. $\mathrm{Br} \mathrm{J}$ Plast Surg 1977;30:1-8. https://doi.org/10.1016/s00071226(77)90026-1

30. Morita D, Numajiri T, Nakamura H. et al. Two cases of the vascular territory of a single-pedicled deep inferior epigastric perforator flap with a vertical midline abdominal scar. Plast Reconstr Surg 2020;8:2684. https://doi.org/10.1097/GOX.0000000000002684

31. Nykiel M, Hunter C, Lee GK. Algorithmic approach to the design and harvest of abdominal flaps for microvascular breast reconstruction in patients with abdominal scars. Ann Plast Surg 2015;74:33-40. https://doi.org/10.1097/SAP.0000000000000509

32. Yılmaz KB, Gurunluoglu R, Bayramiçli M. Flap survival after previous vascular pedicle division and preexisting scar formation at the pedicle site: an experimental study. Ann Plast Surg 2014;73:434-440. https://doi. org/10.1097/SAP.0b013e31827fb346

Bu çalışma, 11-15 Nisan 2018 tarihinde Antalya da yapılan 21. Ulusal Cerrahi Kongresinde, SS-068 kaydı ile sözlü bildiri olarak sunulmuştur.

Çalışma, 1997 yılında yapılan uzmanlık tezinin yeni literatürler ışığında tekrar ele alınması ile üretilmiştir. 2010 yılından önce tamamlandığı için etik kurulu onayı alınmamıştır.

\section{Yazarların makaleye olan katkıları}

R.H.Ö. çalışmanın ana fikrini ve hipotezini kurgulamış, teoriyi geliştirmiş, gereç ve yöntem bölümünü düzenlemişlerdir. Sonuçlar kısmındaki verilerin değerlendirmesini kendisi yapmıştır. Makalenin tartışma bölümü R.H.Ö. tarafından yazılmış, gözden geçirip gerekli düzeltmeleri yapmış ve çalışmanın tamamını tartışmış ve son halini onaylamıştır. 